\title{
Vertical redistribution of drifting benthic invertebrates in the Kedrovaya River, Primorsky Region of Russia
}

\author{
Maxim V. Astakhov*, Victor V. Bogatov \\ Institute of Biology and Soil Sciences, Russian Academy of Sciences, Vladivostok, Russia; \\ *Corresponding Author: mvastakhov@mail.ru
}

Received 31 December 2013; revised 28 January 2014; accepted 7 February 2014

Copyright (c) 2014 Maxim V. Astakhov, Victor V. Bogatov. This is an open access article distributed under the Creative Commons Attribution License, which permits unrestricted use, distribution, and reproduction in any medium, provided the original work is properly cited. In accordance of the Creative Commons Attribution License all Copyrights (C) 2014 are reserved for SCIRP and the owner of the intellectual property Maxim V. Astakhov, Victor V. Bogatov. All Copyright (C) 2014 are guarded by law and by SCIRP as a guardian.

\section{ABSTRACT}

The vertical distribution of morphologically different drifting invertebrates (mayfly and dipteran larvae) in a small salmon river was studied. Drifting invertebrates were caught with the Astakhov's sampler equipped with three driftnets placed one above another. The average annual drift rate in different levels of a water column was practically the same, while the drift density decreased from the bottom to the surface. Over the course of 24 hours, the drifting organisms did not show clear preference for a particular water layer. Invertebrates were constantly redistributed between the upper and lower levels at approximately 30 - 90 min intervals. This redistribution appears to be linked to the fact that invertebrates of the same taxa, which entered into water column from different bottom sites become active at different times.

\section{KEYWORDS}

\section{Sampling; Benthos; Stream Drift; Vertical Distribution}

\section{INTRODUCTION}

The small amount of data available regarding the vertical distribution of drifting benthic invertebrates in streams is contradictory. Basically, it is connected with dynamism of invertebrates' drift process. This is also linked to the fact that researchers used different parameters to perform quantitative assessments of drift: either the drift density (the number and/or biomass of inverte- brates in a given volume of water), or the drift rate (the number and/or biomass of invertebrates carried through a defined cross section of water flow for a fixed interval of time). The observations were also conducted in different seasons and in parts of rivers with different hydrological conditions. For example, Fenoglio and coauthors [1] concluded that in the Erro River (Italy) over the course of a year, drifting invertebrates were most abundant in the bottommost level. On the other hand, the intensity of drift in the lower stratum of the Khor River (Russia) consisted of only $20 \%-25 \%$ of the catch from the upper level [2]. Cellot [3,4] noted a quite even distribution of drift density within the water column, as well as its higher density in the bottommost horizon, under the conditions present in the Rona River (France). Benke and coauthors [5] observed an even distribution in the Satilla River (USA). In large mountain rivers of the Kamchatka Peninsula (Russia), the number and biomass of drifting benthic invertebrates near the surface differed insignificantly from those near the bottom. In the Bystraya River, the density of drifters at the surface was $8 \%$ lower than that at the bottom, and the biomass of migrants at the surface was $12 \%$ lower than that at the bottom. In the Paratunka River, migrant biomass was $18 \%$ greater near the surface, while their number was the same [6].

Different taxonomic groups of zoobenthos may exhibit different behaviours. This was observed in Valley Creek (USA), where the drift rate of amphipods during the period of the evening maximum was practically the same throughout the vertical extent of the stream, while the drift rate of Baetis larvae was higher in the surface level [7]. In the Mississippi River (USA), the night density of mayfly larvae in the upper layer was more than twice as high as that in the lower, while caddis fly larvae pre- 
ferred to migrate along the bottom at all times of the day [8]. In the Kozhim River (Russia), a reduction in the number and biomass of individuals by volume of water from the bottom to the surface was the characteristic of water mites and dipteran larvae. For oligochaeta worms and stonefly larvae, the opposite trend was observed. In the same river, from the riverbed to the surface, an increase in number and a decrease in biomass were found for mayfly larvae, whereas the opposite tendency was noticed in chironomid larvae [9]. In the Mologa River (Russia) during spring flooding, an increase in the densities of oligochaeta worms and mayfly larvae during daylight hours was seen at the middle and lower levels, while nematode worms and chironomid larvae were more frequent at the surface level. However, the total daytime density of invertebrates was higher at the bottommost level [10]. Additionally, daytime observations in the Varzuga River (Russia) showed that the greatest drift density was typically at the surface level [11].

The vertical distribution of drifting organisms during the daytime is associated with the various light levels at different strata of the stream [12-14]. It has also been reported that during the transition from day to night, an inversion in the drift stratification occurs. For example, in the Volga River (Russia), the daytime number of migrants close to the bottom is almost twice as high as at the surface level; in periods of darkness, the opposite is true, with the number of migrants at the surface level twice as high as the number close to the bottom [14]. According to the data reported by Chebanova and coauthors [15], changes in light levels in the water column resulting from even small differences in the depth of the water column have a considerable effect on the vertical distribution of migrants and the length of time they spend in the stream. For example, it was established that in Pravy Kichchik River (Russia), with a depth of $0.6 \mathrm{~m}$, the duration of daytime active migration near the bottom was usually longer than at the surface.

The aim of the current study was to investigate the vertical distribution of drifting benthic invertebrates in a typical salmon river in the southern part of Far East Russia. Sampling was carried out in different seasons of the year at night and during the day to measure two parameters: drift density and drift rate.

\section{MATERIAL AND METHODS}

The Kerdovaya River $\left(43^{\circ} 05^{\prime} \mathrm{N}, 131^{\circ} 35^{\prime} \mathrm{E}\right)$ flows through a mountainous terrain with a coniferous-broadleaf forest in the Primorsky Region of Russia and runs into the Amur Bay of the Sea of Japan. The length of this river is $18 \mathrm{~km}$, and its catchment area is 45.4 square $\mathrm{km}$. The bottom of the river is mostly gravel-pebbled. The river does not suffer from human pollution, as it passes through the Kedrovaya Pad State Natural Biosphere Re- serve. The average annual air temperature in the river basin is $4^{\circ} \mathrm{C}$. Winter is relatively mild, although in January, the air temperature can fall to $-36^{\circ} \mathrm{C}$. As a rule, the first half of summer is cool with lingering rain and drizzle. In the second half of summer air temperature reaches $35^{\circ} \mathrm{C}$. The river freezes at the beginning of December, and thawing occurs in April.

The invertebrate drift characteristics were studied monthly from June 2006 through May 2007. To avoid the influence of moonlight on the night activity of drifting invertebrates, sampling series were carried out in the phase of the new moon. The water temperature during the observations ranged from $0.1^{\circ} \mathrm{C}-0.7^{\circ} \mathrm{C}$ in the winter months to $15^{\circ} \mathrm{C}$ in August. The speed of the flow was measured using a hydrometric current meter GR-55 on three levels corresponding to the position of the nets: near the bottom, in the middle stratum, and near the surface. The average yearly speeds of the current at these levels were $0.42,0.53$ and $0.67 \mathrm{~m} / \mathrm{sec}$, respectively. The average speed of the current throughout the water column changed from $0.25 \mathrm{~m} / \mathrm{sec}$ in January to $0.85 \mathrm{~m} / \mathrm{sec}$ in May. In the warm period (from April to October), it was $0.66 \mathrm{~m} / \mathrm{sec}$, while in the cold period (from November to March) it was $0.37 \mathrm{~m} / \mathrm{sec}$.

Sampling was performed with the Astakhov sampler $[16,17]$ equipped with three drift nets placed one above another. Each net had an entrance with a width of $0.25 \mathrm{~m}$ and a height of $0.1 \mathrm{~m}$. The depth of the nets was $0.6 \mathrm{~m}$, and the mesh size of the nets was 220 microns. During each sampling, the device was installed into a river site with depth, which corresponded to the total height of nets- $0.3 \mathrm{~m}$. At night drifting invertebrates were sampled every hour (25 - 26 June and 25 - 26 July-every 30 minutes), and in the daytime, every 2 hours. The duration of each sampling was 5 minutes. All 687 samples collected were fixed in $4 \%$ formaldehyde solution.

The drift rate at every water level was defined as the value of 5-min catch. The drift density was calculated by dividing of the catch by the volume of water filtered. The vertical distribution was estimated separately for day and night periods. The proportion of daytime and nocturnal drifters in each level was assessed based on the total amount of 24-hr caught (for both density and biomass). For a more general assessment of the vertical stratification in drift, an average annual drift rate and an average annual drift density were calculated.

\section{RESULTS}

Throughout the period of observation, the drifting invertebrates in the Kedrovaya River were dominated by mayfly larvae (Ephemeroptera) from three families: Baetidae (except December and March), Heptageniidae (except July, August and September) and Ephemerellidae (dominant from November to May). Other dominant 
invertebrates included dipteran larvae (Diptera) from two families: Chironomidae (dominant throughout the year) and Simuliidae (dominant in July and August). Among the other invertebrates increased activity was noted in water mites (Hydracarina), stonefly larvae (Plecoptera), caddis fly larvae (Trichoptera), oligochaeta worms (Oligochaeta) and amphipods [17].

The vertical distribution of each of the dominant groups of invertebrates - the Ephemeroptera and Diptera - in terms of drift rate exhibited its own peculiarities (Table 1). For mayfly larvae, an excess of night drifters over daytime migrants was observed at all water levels in the warm period of the year-from May to October. In November and December the predominance of the nighttime drift over the daytime drift was found to be less considerable. From January to April, an increase in the number of night migrants was observed only in the middle and upper levels, but in bottom levels daytime drifters were predominant. Generally the proportion of biomass under night conditions was higher. In the cold season (with the exception of December) the amount of biomass during the day presented a greater value at the lower strata. In the coldest month (January), the proportion of daytime catches in the bottom level was the maximum for the whole period of observation. The vertical distribution of dipterous larvae in terms of drift rate was more mixed. The high biomass of dipterans in night catches on the surface level coincided in time with the large emergence of chironomids in May, August and October. Under conditions of the lowest water temperatures (January), the ratio of daytime drifters increased dramatically with increased depth. In the meantime, the proportion of night catches fell correspondingly. As a result, the catch of dipterans in the lower layer reached a maximum for the entire period of daylight observations.

The distribution of mayfly and dipteran larvae by volume of water (drift density) showed a similar pattern to the corresponding values of drift rate (Tables 1 and 2). One difference was that there was a more accelerated increase in the proportion of the density of drifting larvae with increasing river depth, in terms of both number and biomass. For example, if in June, the numbers of mayflies in night catches in the top, middle and lower levels were $21 \%$, 22\% and 26\%, respectively, from 24-hour values, then their proportions of total drift density at the same levels were $16 \%, 21 \%$ and $32 \%$, respectively.

During the warm season, the average mass of mayfly larvae (individual weight-an indirect indicator of the developmental stage) in daytime was one-third the average mass of larvae that preferred to migrate at night. In the cold season in the daytime, too, was dominated by individuals of smaller sizes, with the exception of the January, when the average body weights of day and night migrants were nearly identical, presenting values of 0.11 and $0.12 \mathrm{mg}$, respectively. Regarding the distribution of larvae of different sizes in the water column, the largest mature may fly larvae (with body masses over $2 \mathrm{mg}$ ) migrated in the lower strata. At the same time, mayflies from the middle and the upper horizons were found to weigh half as much (Figure 1). As for the vertical distribution of the largest dipteran individuals, it may be noted that they preferred to drift closer to the surface (Figure 1).

The calculation of average annual characteristics (in terms of catches and density) showed that, independently of the changes in current velocity due to depth, similarity in drift rates for both Ephemeroptera and Diptera was revealed (Figure 2). Against the background of the unchanging drift rate of invertebrates, their average annual density was successively reduced from the bottommost stratum to the surface level (Figure 2).

The sampling conducted at intervals of 30 minutes confirmed that drifters do not remain in definite layer of water very long. For both drifting mayfly and dipteran larvae a constant redistribution between the upper and lower levels of the stream was noticed, with approximate intervals of 30 - 90 minutes. The exception was the two-hour period of increased migration activity observed in July just after nightfall (Figure 3).

\section{DISCUSSION}

The earliest research on invertebrate drift showed that during dark periods of the day, many benthic invertebrates are able to shift their masses upwards into the water column and move downstream [12,18,19]. Mayfly larvae have always been considered to be prone to nocturnal activity while dipteran larvae showed no general pattern of drift periodicity [20]. According to other sources dipterans, particularly chironomid larvae, were observed to be highly active at night in conditions of large submountain rivers [21]. It is clear that the daytime drift allows invertebrates to orient themselves visually in a space during new substrate selection, though this makes them more vulnerable to predators. That is why the active drift of most invertebrates occurs in the night time. However, year-round research carried out in the Kedrovaya River showed that, in contrast to the warm season, in conditions of ice cover a large movement of organisms within a water column was observed also in daytime, and the number of daytime drifters exceeded those at night $[22,23]$. It is likely that in the cold season, with conditions of low feeding activity among fish, the effectiveness of daylight invertebrate drift is no lower than at night, especially for the less visible smallest individuals [17].

The present study of the vertical distribution of drifting invertebrates showed that in the cold season for mayfly larvae an excess of daytime drift rate over night- 
Table 1. Percentage of the total daily drift of Ephemeroptera and Diptera larvae in terms of drift rate. U, M, B-the upper, the middle and the bottommost layer. Bold type—nighttime data, regular-daytime data.

\begin{tabular}{|c|c|c|c|c|c|c|c|c|c|c|c|c|c|c|}
\hline \multirow{2}{*}{ Group } & \multirow{2}{*}{ Parameter } & \multirow{2}{*}{ Layer } & \multicolumn{12}{|c|}{ Month } \\
\hline & & & Jun & Jul & Aug & Sep & Oct & Nov & Dec & Jan & Feb & Mar & Apr & May \\
\hline \multirow{12}{*}{ 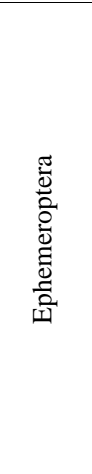 } & \multirow{6}{*}{ Number } & \multirow{2}{*}{$\mathrm{U}$} & 21.2 & 26.7 & 32.9 & 30.4 & 16.6 & 22.0 & 24.7 & 11.4 & 21.6 & 21.0 & 22.8 & 19.6 \\
\hline & & & 8.8 & 5.0 & 4.5 & 6.0 & 6.6 & 3.2 & 23.7 & 3.4 & 9.8 & 4.7 & 10.1 & 7.3 \\
\hline & & \multirow{2}{*}{ M } & 22.1 & 33.8 & 26.9 & 33.5 & 25.2 & 21.4 & 16.4 & 12.5 & 23.9 & 21.9 & 18.7 & 26.0 \\
\hline & & & 8.6 & 4.4 & 3.5 & 4.1 & 7.9 & 16.3 & 14.0 & 5.7 & 8.2 & 6.8 & 10.5 & 9.8 \\
\hline & & \multirow{2}{*}{ B } & 25.7 & 24.6 & 22.9 & 21.2 & 35.8 & 25.8 & 13.7 & 16.1 & 17.8 & 19.7 & 16.4 & 24.5 \\
\hline & & & 13.5 & 5.5 & 9.3 & 4.8 & 7.9 & 11.3 & 7.5 & 50.9 & 18.8 & 26.0 & 21.5 & 12.8 \\
\hline & \multirow{6}{*}{ Biomass } & \multirow{2}{*}{$\mathrm{U}$} & 26.4 & 30.2 & 39.9 & 33.3 & 27.9 & 13.1 & 23.7 & 19.5 & 18.2 & 26.5 & 27.0 & 33.2 \\
\hline & & & 1.3 & 3.2 & 0.8 & 3.3 & 2.2 & 1.8 & 13.2 & 3.9 & 6.7 & 2.2 & 5.1 & 0.9 \\
\hline & & \multirow{2}{*}{ M } & 29.0 & 30.6 & 24.3 & 41.5 & 38.8 & 16.7 & 26.6 & 10.9 & 27.3 & 27.6 & 28.8 & 29.8 \\
\hline & & & 1.0 & 2.1 & 2.2 & 1.3 & 4.2 & 7.2 & 8.8 & 4.9 & 4.5 & 4.3 & 3.9 & 2.5 \\
\hline & & \multirow{2}{*}{ B } & 35.9 & 30.3 & 29.9 & 18.8 & 22.0 & 37.7 & 22.6 & 11.9 & 27.8 & 24.8 & 24.9 & 31.5 \\
\hline & & & 6.3 & 3.5 & 3.1 & 1.6 & 4.9 & 23.4 & 5.2 & 49.0 & 15.5 & 14.6 & 10.4 & 2.0 \\
\hline \multirow{12}{*}{ 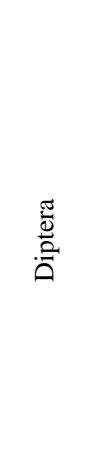 } & \multirow{6}{*}{ Number } & \multirow{2}{*}{$\mathrm{U}$} & 14.3 & 18.0 & 22.1 & 16.8 & 41.1 & 29.9 & 9.9 & 15.4 & 23.8 & 13.2 & 11.6 & 19.1 \\
\hline & & & 27.7 & 14.2 & 24.0 & 22.9 & 23.3 & 8.4 & 29.6 & 4.6 & 12.3 & 19.4 & 21.7 & 19.3 \\
\hline & & \multirow{2}{*}{ M } & 9.0 & 19.2 & 13.3 & 21.4 & 19.2 & 17.9 & 21.1 & 14.4 & 20.1 & 10.6 & 13.5 & 12.8 \\
\hline & & & 17.2 & 15.1 & 12.8 & 15.4 & 8.2 & 8.1 & 25.2 & 23.7 & 10.7 & 20.8 & 21.0 & 19.3 \\
\hline & & \multirow{2}{*}{ B } & 11.0 & 18.1 & 10.2 & 11.2 & 8.2 & 20.8 & 5.7 & 6.5 & 20.6 & 12.8 & 11.6 & 12.7 \\
\hline & & & 20.7 & 15.4 & 17.6 & 12.3 & 0.0 & 14.9 & 8.5 & 35.3 & 12.5 & 23.2 & 20.6 & 16.7 \\
\hline & \multirow{6}{*}{ Biomass } & \multirow{2}{*}{$\mathrm{U}$} & 16.3 & 21.7 & 43.5 & 16.5 & 66.1 & 19.2 & 8.2 & 26.9 & 27.3 & 12.1 & 11.6 & 34.0 \\
\hline & & & 30.6 & 11.7 & 13.8 & 16.9 & 3.8 & 15.0 & 21.5 & 1.5 & 5.8 & 22.9 & 17.2 & 11.0 \\
\hline & & \multirow{2}{*}{ M } & 11.8 & 26.1 & 17.1 & 39.1 & 18.5 & 33.3 & 37.1 & 15.8 & 22.9 & 9.7 & 18.8 & 16.2 \\
\hline & & & 12.9 & 9.1 & 4.7 & 9.6 & 9.0 & 11.0 & 19.7 & 10.2 & 7.3 & 21.5 & 18.7 & 11.9 \\
\hline & & \multirow{2}{*}{ B } & 18.3 & 23.3 & 10.9 & 11.0 & 2.6 & 17.1 & 5.0 & 14.7 & 27.5 & 12.5 & 14.4 & 16.0 \\
\hline & & & 10.1 & 8.1 & 10.0 & 6.9 & 0.0 & 4.4 & 8.5 & 30.9 & 9.2 & 21.4 & 19.3 & 11.0 \\
\hline
\end{tabular}

Table 2. Percentage of the total daily drift of Ephemeroptera and Diptera larvae in terms of drift density. Designations as in Table $\mathbf{1 .}$

\begin{tabular}{|c|c|c|c|c|c|c|c|c|c|c|c|c|c|c|}
\hline \multirow{2}{*}{ Group } & \multirow{2}{*}{ Parameter } & \multirow{2}{*}{ Layer } & \multicolumn{12}{|c|}{ Month } \\
\hline & & & Jun & Jul & Aug & Sep & Oct & Nov & Dec & Jan & Feb & Mar & Apr & May \\
\hline \multirow{12}{*}{ 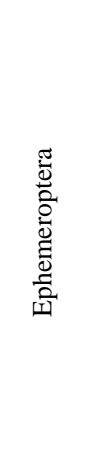 } & \multirow{6}{*}{ Number } & \multirow{2}{*}{$\mathrm{U}$} & 15.8 & 24.4 & 27.6 & 26.8 & 12.7 & 14.9 & 16.7 & 6.8 & 15.7 & 15.1 & 20.2 & 16.3 \\
\hline & & & 6.4 & 4.6 & 3.5 & 5.3 & 5.2 & 2.1 & 17.4 & 1.7 & 6.5 & 3.1 & 8.4 & 6.0 \\
\hline & & \multirow{2}{*}{ M } & 21.3 & 34.2 & 28.4 & 33.6 & 24.6 & 20.2 & 15.3 & 12.5 & 24.7 & 24.7 & 18.7 & 25.3 \\
\hline & & & 8.1 & 4.4 & 3.5 & 4.1 & 8.0 & 14.6 & 14.2 & 4.7 & 7.8 & 7.0 & 9.9 & 9.3 \\
\hline & & \multirow{2}{*}{ B } & 32.0 & 26.5 & 26.7 & 24.7 & 40.2 & 34.1 & 22.8 & 20.7 & 23.0 & 22.8 & 19.1 & 28.5 \\
\hline & & & 16.5 & 5.9 & 10.3 & 5.5 & 9.2 & 14.2 & 13.5 & 53.7 & 22.4 & 27.3 & 23.7 & 14.6 \\
\hline & \multirow{6}{*}{ Biomass } & \multirow{2}{*}{$\mathrm{U}$} & 19.4 & 27.6 & 33.5 & 29.7 & 22.6 & 8.1 & 14.9 & 13.1 & 12.4 & 19.1 & 23.6 & 28.1 \\
\hline & & & 0.8 & 2.9 & 0.6 & 3.0 & 1.7 & 1.0 & 9.4 & 1.9 & 4.3 & 1.5 & 4.3 & 0.8 \\
\hline & & \multirow{2}{*}{ M } & 27.7 & 30.9 & 25.6 & 42.0 & 40.1 & 14.3 & 23.0 & 12.1 & 26.8 & 31.2 & 28.4 & 29.3 \\
\hline & & & 0.9 & 2.1 & 2.1 & 1.4 & 4.1 & 5.6 & 8.6 & 4.0 & 4.2 & 4.4 & 3.7 & 2.4 \\
\hline & & \multirow{2}{*}{ B } & 44.3 & 32.7 & 34.8 & 22.0 & 26.1 & 45.2 & 34.9 & 17.1 & 34.1 & 28.6 & 28.6 & 37.1 \\
\hline & & & 6.9 & 3.8 & 3.3 & 1.9 & 5.5 & 25.7 & 9.2 & 51.8 & 18.1 & 15.3 & 11.4 & 2.3 \\
\hline \multirow{12}{*}{ 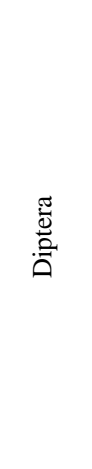 } & \multirow{6}{*}{ Number } & \multirow{2}{*}{ U } & 11.1 & 16.4 & 19.1 & 14.9 & 36.3 & 21.5 & 6.8 & 10.4 & 17.2 & 9.6 & 10.1 & 16.5 \\
\hline & & & 21.5 & 12.9 & 20.2 & 20.4 & 21.7 & 5.4 & 22.0 & 2.5 & 8.8 & 13.8 & 18.9 & 16.4 \\
\hline & & \multirow{2}{*}{ M } & 9.0 & 19.3 & 14.3 & 21.5 & 21.6 & 17.9 & 20.1 & 16.4 & 20.7 & 12.0 & 13.3 & 12.9 \\
\hline & & & 17.2 & 15.2 & 13.5 & 15.7 & 9.8 & 7.3 & 25.8 & 21.0 & 10.9 & 23.1 & 20.7 & 19.1 \\
\hline & & \multirow{2}{*}{ B } & 14.3 & 19.6 & 12.2 & 13.0 & 10.6 & 29.1 & 9.8 & 9.5 & 26.6 & 14.9 & 13.3 & 15.3 \\
\hline & & & 26.9 & 16.6 & 20.6 & 14.5 & 0.0 & 18.8 & 15.5 & 40.2 & 15.9 & 26.4 & 23.7 & 19.8 \\
\hline & \multirow{6}{*}{ Biomass } & \multirow{2}{*}{ U } & 12.2 & 19.7 & 38.9 & 14.6 & 61.7 & 13.5 & 5.7 & 18.2 & 19.4 & 8.8 & 10.0 & 29.9 \\
\hline & & & 25.6 & 10.8 & 11.8 & 15.3 & 3.2 & 11.7 & 15.3 & 0.7 & 4.0 & 16.6 & 14.9 & 9.2 \\
\hline & & \multirow{2}{*}{ M } & 11.4 & 26.3 & 19.2 & 39.2 & 22.0 & 32.7 & 35.9 & 17.9 & 23.3 & 11.0 & 18.4 & 16.6 \\
\hline & & & 13.9 & 9.3 & 5.0 & 9.8 & 9.6 & 12.0 & 19.4 & 8.5 & 7.1 & 24.4 & 18.3 & 11.7 \\
\hline & & \multirow{2}{*}{ B } & 22.8 & 25.1 & 13.5 & 12.8 & 3.6 & 23.5 & 8.7 & 21.3 & 35.0 & 14.5 & 16.4 & 19.6 \\
\hline & & & 14.1 & 8.9 & 11.8 & 8.3 & 0.0 & 6.7 & 15.0 & 33.3 & 11.3 & 24.8 & 22.0 & 13.0 \\
\hline
\end{tabular}




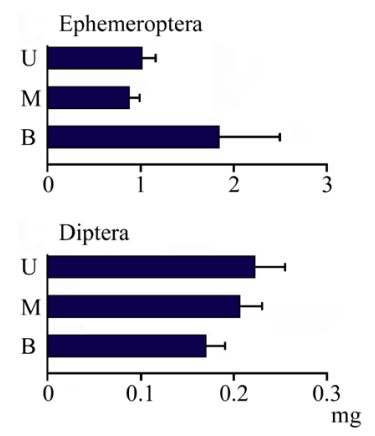

Figure 1. An average annual body mass of drifting Ephemeroptera and Diptera larvae. U, M, B-the upper, the middle and the bottommost layer. Error bars denote standard error.

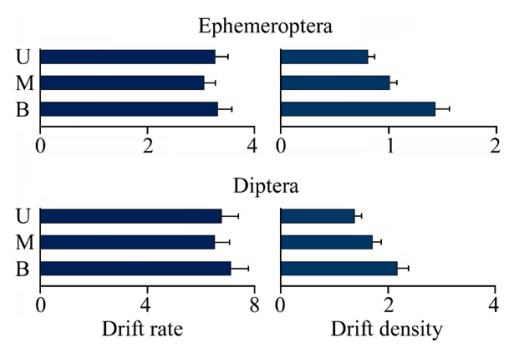

Figure 2. An average annual number of drifting Ephemeroptera and Diptera larvae in terms of the drift rate (individuals per 5 min catch) and drift density (individuals per $\mathrm{m}^{3}$ ). Designations as in Figure 1.

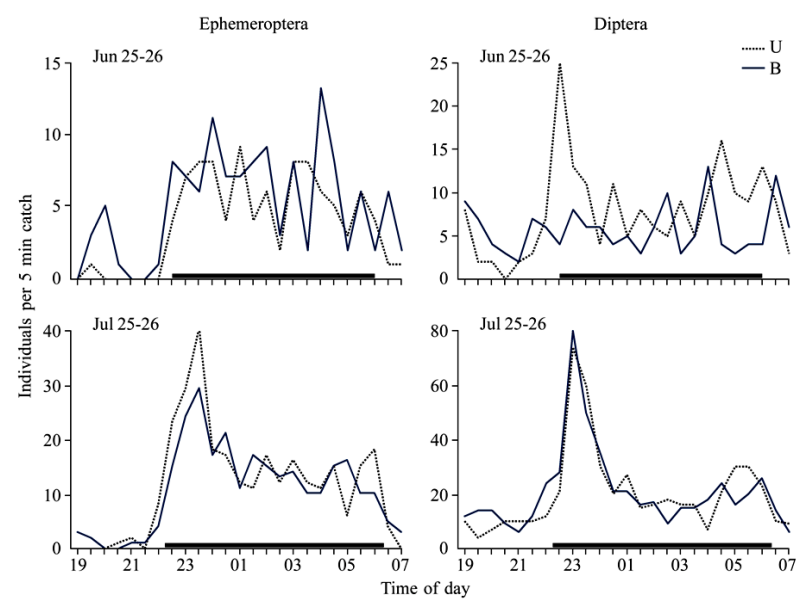

Figure 3. Dynamics of the vertical redistribution of drifting Ephemeroptera and Diptera larvae. U-the upper, B-the bottommost layer. Thick black lines denote a night period.

time drift rate was observed exclusively in the lower strata. In the most coldest month (January) the drift values in the lower horizon were so high that the total daytime drift of mayflies was higher than their total drift at night. Nevertheless during the warm season mayfly larvae repeatedly showed a typical night-type activity without a reliable preference for a particular stream level. With regard to dipteran larvae, their prevalence in the daytime drift throughout the water column was noted as early as December and was observed during the entire winter-spring period (with the exception of February). A more diverse pattern was observed in the warm season due periodic activation of night-drifting of adult chironomid larvae before pupation and emergence. Note that in January, during daylight hours, drifting mayfly and dipteran larvae concentrated to a large extent in the lower stratum. Obviously, in conditions, when water temperature was close to the freezing point the ability of the daytime migrants to swim was limited. However, those organisms with neutral or positive buoyancy could reach the surface because of the turbulent agitation of the water. It has been established that in a turbulent stream the upward flow has a higher speed than downward current. For example, at a flow velocity of $0.45 \mathrm{~m} / \mathrm{sec}$, the vertical component of turbulent transfer was $1.2 \mathrm{~cm} / \mathrm{sec}$ [24]. Nevertheless, in the Kedrovaya River a large proportion of day migrants remained in the lower level, while night drifters were distributed in the water column more evenly. Based on these findings, two assumptions can be made. The first one is about the lower buoyancy of daytime migrants in comparison to that of night migrants (if the drift of these groups occurs separately). The second is about the ability of invertebrate larvae to change their activity patterns and buoyancy in the course of a day (if the same larvae participate in drift during the day and at night).

Integration of the data for the whole period of observation sheds light on general principles related to the vertical stratification in drift. The average annual drift rate of the studied invertebrates in different levels of the water column was practically the same, while their distribution in a volume of water decreased from the bottom to the surface. The general pattern for both mayfly and dipteran larvae is similar in the integrated parameters, which are comparable with the classic pattern of suspended particle transportation [25]. These circumstances show a particular passivity of invertebrate movement in the river stream. Thus, in the most general view, we may discuss that invertebrates actively rise to the upper layers of the water column, and then passively drift downstream. The distinctive feature of such a method of migration is its use of the motive forces in the water, allowing invertebrates to travel greater distances without additional energy expenditure. The passive mode of moving with the flow is mainly linked to the physical inability of invertebrates to resist the current, as the speed of migrant drift is nearly the same as the speed of the current. It is known that the vertical distribution of suspended par- 
ticles in a river stream is defined by their hydraulic size (that is, the speed with which a particle sinks in stagnant water) and the stream velocity. As such, the probability of large, suspended particles with a diameter of $>0.15$ $\mathrm{mm}$ reaching the upper level of the stream is relatively low [25]. Mayfly and dipteran larvae differs morphologically to a large extent. In particular, mayfly larvae have well-developed limbs and cerci for active swimming, while dipteran larvae are worm-shaped and do not have the same swimming abilities, although they can move in the stream by bending their bodies. Meanwhile in the Kedrovaya River the largest mature dipteran larvae drifted near the surface, and this indicates not only the active character of their rising into the water column, but also their ability to maintain their position in the upper stratum. This is especially true for chironomid pupae, for which a rapid rise to the surface in preparation for emergence occurs as a result of the formation of an air bubble in a cephalothorax region [26]. A similar air bubble forms in some adult mayfly larvae (Baetidae). The emergence of other mayflies (for example, in Heptageniidae and Ephemerellidae) mainly occurs in coastal areas [27], which limits the possibility of their mature larvae to appear within the upper layer of the main channel.

Revealed "wavy" pattern in the vertical redistribution of drifting invertebrates (Figure 3) may be linked to the fact that the same taxa can become active in different local regions of a stream at different times and then complete their elevation to the surface in compact groups. If the large entrance of drifters up to the stream surface occurs from different sites and at different moments, invertebrates elevating from the closest bottom site will be found in the lower horizon and those rising from the distant sites will be present in the upper strata. It is clear that in the period of active invertebrate surfacing and during their subsequent drift, there is a dispersal of drifters vertically due to the turbulent shifting of water. Due to this high stream turbulence, the distribution of organisms in the stream at the final stage of drift should be more even.

The above hypothesis requires careful empirical testing, as the mechanisms related to the completion of invertebrate drift remain unknown. It is possible that certain invertebrates participating in the drift are able to rise into a water column several times a day in search of suitable biotopes, whereas others are not able to take part in drift at all. For example, fish in rivers is clearly divided into two groups: one that participates in downstream migration and another that does not [24]. The similar behaviour of many bottom invertebrates indicates circumstances in which even in the most active types of migrants in the upper regions of the habitat remain individuals that end their cycles of development exactly at this point [28].
The varying characteristics of drifters risings would appear to be explained by physiological differences related to the behaviour of disconnected groups of invertebrates and the heterogeneity of their habitats with respect to key factors, such as turbulence, depth, flow velocity, features of the river bottom, lighting conditions, and the availability of shelters. It is undeniable that turbulent shifting of water and the buoyancy of hydrobionts can have a significant effect on the vertical distribution of organisms in a water column. At least it has been established that hatchlings of semi-anadromous fish after large downstream migration are able to change their buoyancy from negative in the daytime to positive at night $[24,29]$. Whether benthic invertebrates possess similar abilities remains unknown.

\section{CONCLUSION}

The vertical distribution of drifting benthic invertebrates is distinguished by its diversity and is associated mainly to their morphological features and developmental stage, as well as the season and lighting conditions. For dipteran larvae, the largest mature individuals generally drifted in the upper level, while in mayfly larvae such individuals were most often in the bottom level. The general drift pattern was comparable with the classic pattern of suspended particles distribution in a water column. At the same time, the examined benthic invertebrates have demonstrated the ability to enter into water at their own initiative, and to maintain their position within the surface layer. Our results confirmed the importance of simultaneous consideration of the drift rates and drift densities in the interpretation of data on the vertical distribution of drifting invertebrates.

\section{ACKNOWLEDGEMENTS}

The work was carried out with the support of the Program of the Presidium of the Russian Academy of Sciences (project 09-I-DBS-01) and via a grant from the Far Eastern Division of the Russian Academy of Sciences (project 12-I-П30-01).

\section{REFERENCES}

[1] Fenoglio, S., Bo, T., Gallina, G. and Cucco, M. (2004) Vertical distribution in the water column of drifting stream macroinvertebrates. Journal of Freshwater Ecology, 19, 485-492.

http://dx.doi.org/10.1080/02705060.2004.9664923

[2] Levanidova, I.M. and Levanidov, V.Ya. (1965) Diurnal migrations of benthal insect larvae in the river stream (Migration of Ephemeroptera larvae in the Khor River). Zoologicheskii Zhurnal, 44, 375-385.

[3] Cellot, B. (1989) Macroinvertebrate movements in a large European river. Freshwater Biology, 22, 45-55. http://dx.doi.org/10.1111/j.1365-2427.1989.tb01082.x 
[4] Cellot, B. (1996) Influence of side-arms on aquatic macroinvertebrate drift in the main channel of a large river. Freshwater Biology, 35, 149-164. http://dx.doi.org/10.1046/j.1365-2427.1996.00490.x

[5] Benke, A.C., Hunter, R.J. and Parrish, F.K. (1986) Invertebrate drift dynamics in a subtropical blackwater river. Journal of the North American Benthological Society, 5, 173-190. http://dx.doi.org/10.2307/1467705

[6] Chebanova, V.V. (2009) Benthos of salmon rivers of Kamchatka. VNIRO Publishing, Moscow.

[7] Waters, T.F. (1965) Interpretation of invertebrate drift in streams. Ecology, 46, 327-334. http://dx.doi.org/10.2307/1936336

[8] Matter, W.J. and Hopwood, A.J. (1980) Vertical distribution of invertebrate drift in a large river. Limnology and Oceanography, 25, 1117-1121.

http://dx.doi.org/10.4319/lo.1980.25.6.1117

[9] Shubina, V.N. (2006) Benthos of salmon rivers of the Ural and Timan Mountains. Nauka, Saint Petersburg.

[10] Ioffe, C.I. (1949) Technique of study of transporting of benthic organisms with a river and its role in the reservoir colonization. Izvestiya Vsesoyuznogo NII Ozernogo I Rechnogo Rybnogo Khozyaystva, 29, 96-105.

[11] Baryshev, I.A. (2001) Rheophil communities of bottom invertebrates of the Onega Lake and the White Sea tributaries. Ph.D. Dissertation, Petrozavodsk University, Petrozavodsk.

[12] Levanidova, I.M. and Levanidov, V.Ya. (1962) On the migrations of the benthic invertebrates in a water column of Far-Eastern Rivers. Izvestiya Tikhookeanskogo NII Rybnogo Khozyaistva I Okeanographii, 48, 178-189.

[13] Kljutschareva, O.A. (1963) On downstream and diurnal vertical migrations of benthic invertebrates in the Amur River. Zoologicheskii Zhurnal, 42, 1601-1612.

[14] Konstantinov, A.S. (1969) Syrton and benthic flow of the Volga River near the town of Saratov in 1966. Zoologicheskii Zhurnal, 48, 20-29.

[15] Chebanova, V.V., Ulatov, A.V. and Leman, V.V. (2004) Comparative characteristics of benthos, drift and juvenile Pacific Salmon abundance in the streams of various types within the basin of the Kikhchik River, West Kamchatka. Research of Water Biological Resources of Kamchatka and of the Northwest Part of Pacific Ocean, 7, 122-130.

[16] Astakhov, M.V. (2012) Stratifying drift sampler. Amurian Zoological Journal, 4, 3-8. http://www.bgpu.ru/azj/distributor.jsp?tom=4\&nomer=1 \&article $=1$

[17] Astakhov, M.V. (2009) Drift of phytobenthos and zoobenthos in the typical Salmon River (Kedrovaya River, Primorsky Region). Ph.D. Dissertation, IMB, Vladivostok.

[18] Tanaka, H. (1960) On the daily change of the drifting of benthic animals in stream, especially on the types of daily change observed in taxonomic groups of insects. Bulletin of Freshwater Fisheries Research Laboratory, 9, 13-24.

[19] Elliott, J.M. (1967) Invertebrate drift in a Dartmoor stream. Archiv Fur Hydrobiologie, 63, 202-237.

[20] Sagar, P.M. and Glova, G.J. (1992) Diel changes in the abundance and size composition of invertebrate drift in five rivers in South Island, New Zealand. New Zealand Journal of Marine and Freshwater Research, 26, 103-114. http://dx.doi.org/10.1080/00288330.1992.9516506

[21] Bogatov, V.V. (1994) Ecology of River Communities of Russian Far East. Dalnauka, Vladivostok.

[22] Astakhov, M.V. (2014) Invertebrate drift in the piedmont part of the Kedrovaya River (Primorsky Region, Russia) in warm season. Inland Water Biology, 7, 48-55.

[23] Bogatov, V.V. and Astakhov, M.V. (2011) Under-ice drift of invertebrates in the piedmont part of Kedrovaya River (Primorskii Krai). Inland Water Biology, 4, 56-64. http://dx.doi.org/10.1134/S1995082911010032

[24] Pavlov, D.S., Lupandin, A.I. and Kostin, V.V. (2007) Mechanisms of downstream migration of young fish living in rivers. Nauka, Moscow.

[25] Alexeevsky, N.I. (2006) Hydrophysics. Akademiya, Moscow.

[26] Konstantinov, A.S. (1958) Chironomids biology and their cultivation. Trudy Saratovskogo Otdeleniya VNII Ozernogo I Rechnogo Rybnogo Khozyaystva, 5, 1-362.

[27] Tiunova, T.M. (1993) Ephemerans of the Kedrovaya River and their ecological and physiological characteristics. Dalnauka, Vladivostok.

[28] Bogatov, V.V. (2005) The main methods for study the river benthos drift. Vladimir Levanidov's Biennial Memorial Meetings, 3, 5-17.

[29] Pavlov, D.S. (1994) The downstream migration of young fishes in rivers: Mechanisms and distribution. Folia Zoologica, 43, 193-208. 